\title{
Molecular Transformations of Unsaturated Thiacrown Ethers
}

\section{Supporting Information}

Takahiro Tsuchiya, ${ }^{\dagger}$ Yosuke Okada, Toshio Shimizu,* Kazunori Hirabayashi, and Nobumasa Kamigata*

Department of Chemistry, Graduate School of Sciences and Engineering, Tokyo Metropolitan University, Minami-ohsawa, Hachioji, Tokyo 192-0397, Japan

\section{Table of Contents}

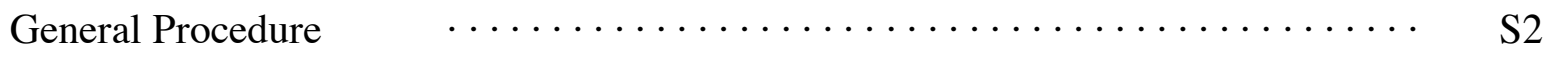

Typical Procedure for the Reactions of $\mathbf{1}-\mathbf{3}$ with $t$ - $\mathrm{BuOCl} \quad \ldots \ldots \ldots \ldots \ldots \ldots$. S2

Typical Procedure for the Photochemical Reaction of $2 \quad \ldots \ldots \ldots \ldots \ldots \ldots . \quad$ S2

Typical Procedure for the Reactions of 2 with NCS, NCP, CBS, and NBP $\ldots \ldots \quad$ S3

${ }^{1} \mathrm{H}$ NMR of Compound $4\left(500 \mathrm{MHz}, \mathrm{CDCl}_{3}\right) \quad \ldots \ldots \ldots \ldots \ldots \ldots \ldots \ldots \ldots \ldots \ldots$

${ }^{13} \mathrm{C}$ NMR of Compound $4\left(125 \mathrm{MHz}, \mathrm{CDCl}_{3}\right) \quad \ldots \ldots \ldots \ldots \ldots \ldots \ldots \ldots \ldots$ S5

${ }^{1} \mathrm{H}$ NMR of Compound $5\left(500 \mathrm{MHz}, \mathrm{DMSO}-d_{6}\right) \quad \ldots \ldots \ldots \ldots \ldots \ldots \ldots \ldots \ldots$ S6

${ }^{13} \mathrm{C}$ NMR of Compound $5\left(125 \mathrm{MHz}, \mathrm{DMSO}-d_{6}\right) \quad \ldots \ldots \ldots \ldots \ldots \ldots \ldots \ldots \ldots \ldots$

${ }^{1} \mathrm{H}$ NMR of Compound $6\left(500 \mathrm{MHz}, \mathrm{CDCl}_{3}\right) \quad \ldots \ldots \ldots \ldots \ldots \ldots \ldots \ldots$

${ }^{13} \mathrm{C}$ NMR of Compound $6\left(125 \mathrm{MHz}, \mathrm{CDCl}_{3}\right) \quad \ldots \ldots \ldots \ldots \ldots \ldots \ldots \ldots$ S9

${ }^{1} \mathrm{H}$ NMR of Compound $7\left(500 \mathrm{MHz}, \mathrm{CDCl}_{3}\right) \quad \ldots \ldots \ldots \ldots \ldots \ldots \ldots \ldots$

${ }^{13} \mathrm{C}$ NMR of Compound $7\left(125 \mathrm{MHz}, \mathrm{CDCl}_{3}\right) \quad \ldots \ldots \ldots \ldots \ldots \ldots \ldots \ldots \ldots \ldots$

${ }^{1} \mathrm{H}$ NMR of Compound $12\left(500 \mathrm{MHz}, \mathrm{CDCl}_{3}\right) \quad \ldots \ldots \ldots \ldots \ldots \ldots \ldots \ldots \ldots \ldots$

${ }^{13} \mathrm{C}$ NMR of Compound $12\left(125 \mathrm{MHz}, \mathrm{CDCl}_{3}\right) \quad \ldots \ldots \ldots \ldots \ldots \ldots \ldots \ldots \ldots \ldots$ 


\section{General Procedure.}

Dichloromethane and methanol were distilled from calcium hydride and magnesium cake, respectively, prior to use. Preparation and purification of 1, 2, and $\mathbf{3}$ have been previously described. $^{8}$

\section{Typical Procedure for the Reactions of Unsaturated Thiacrown Ethers 1-3 with} t-BuOCl. A methanol/dichloromethane $(=1: 2)$ solution $(1 \mathrm{~mL})$ of $t$ - $\mathrm{BuOCl}(0.2 \mathrm{mmol})$ was added to a methanol/dichloromethane $(=1: 2)$ solution $(14 \mathrm{~mL})$ of unsaturated thiacrown ethers $(0.2 \mathrm{mmol})$ under nitrogen. The reaction mixture was stirred for $2 \mathrm{~h}$ at desired temperature, and $2 \mathrm{M} \mathrm{NaOH}$ aq $(0.3 \mathrm{~mL})$ was added to the resulting solution. After the additional stirring for $30 \mathrm{~min}$, the reaction mixture was extracted with dichloromethane, washed with $\mathrm{H}_{2} \mathrm{O}$, and dried over $\mathrm{Na}_{2} \mathrm{SO}_{4}$. The products were isolated by silica-gel column chromatography (hexane/acetone $=1: 1, \mathrm{R}_{f}$ 4: $0.22,5: 0.07,6: 0.11$; hexane/acetone $=2: 1$, $\mathrm{R}_{f}$ 7: $\left.0.38,8: 0.46,9: 0.46\right)$.

\section{Typical Procedure for the Photochemical Reaction of Unsaturated Thiacrown Ether}

2. A freshly distilled toluene solution $(144 \mathrm{~mL})$ of $2(67 \mathrm{mg}, 0.2 \mathrm{mmol})$ was irradiated with a $450 \mathrm{~W}$ medium-pressure mercury lamp through a Pyrex filter under argon for $20 \mathrm{~min}$ at $\mathrm{rt}$. After removal of solvent in vacuo, the residue was subjected to silica-gel column chromatography (hexane/acetone $=2: 1, \mathrm{R}_{f}$ 1,4-dithiin: 0.80, 7: 0.38). 
Typical Procedure for the Reactions of Unsaturated Thiacrown Ether 2 with NCS, NCP, CBS, and NBP. A methanol/dichloromethane $(=1: 2)$ solution $(1 \mathrm{~mL})$ of $N$-chlorosuccinimide (NCS), $N$-chlorophthalimide (NCP), $N$-bromosuccinimide (NBS), or $N$-bromophthalimide (NBP) $(0.2 \mathrm{mmol})$ was added to a methanol/dichloromethane $(=1: 2)$ solution $(14 \mathrm{~mL})$ of $2(0.2 \mathrm{mmol})$ under nitrogen. The reaction mixture was stirred at $\mathrm{rt}$ for $2 \mathrm{~h}$, and $2 \mathrm{M} \mathrm{NaOH}$ aq $(0.3 \mathrm{~mL})$ was added to the resulting solution. After the additional stirring for $30 \mathrm{~min}$, the reaction mixture was extracted with dichloromethane, washed with $\mathrm{H}_{2} \mathrm{O}$, and dried over $\mathrm{Na}_{2} \mathrm{SO}_{4}$. The products were isolated by silica-gel column chromatography (hexane/acetone $=2: 1, \mathrm{R}_{f} \mathbf{1 2}: 0.39$ ). 


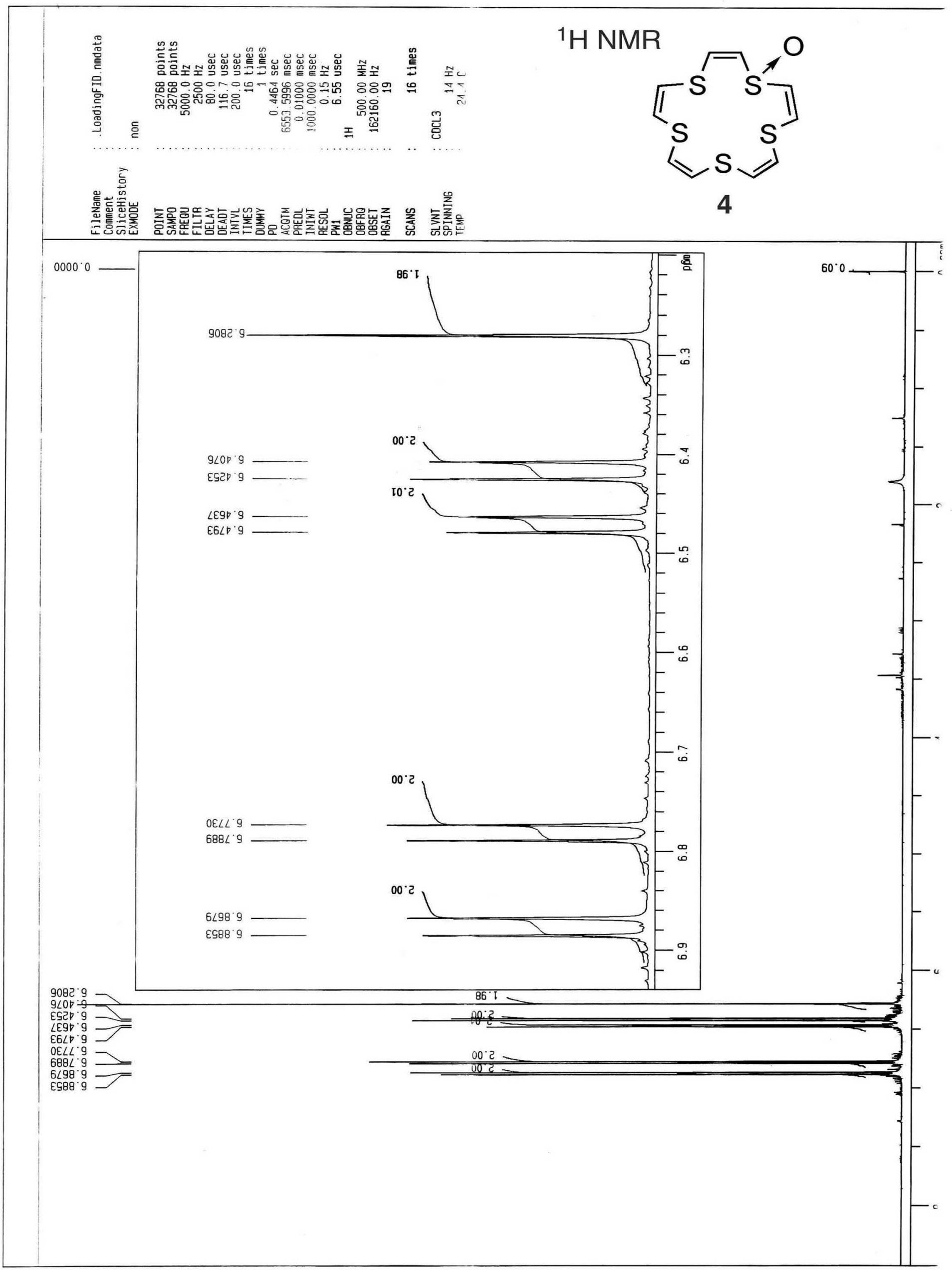




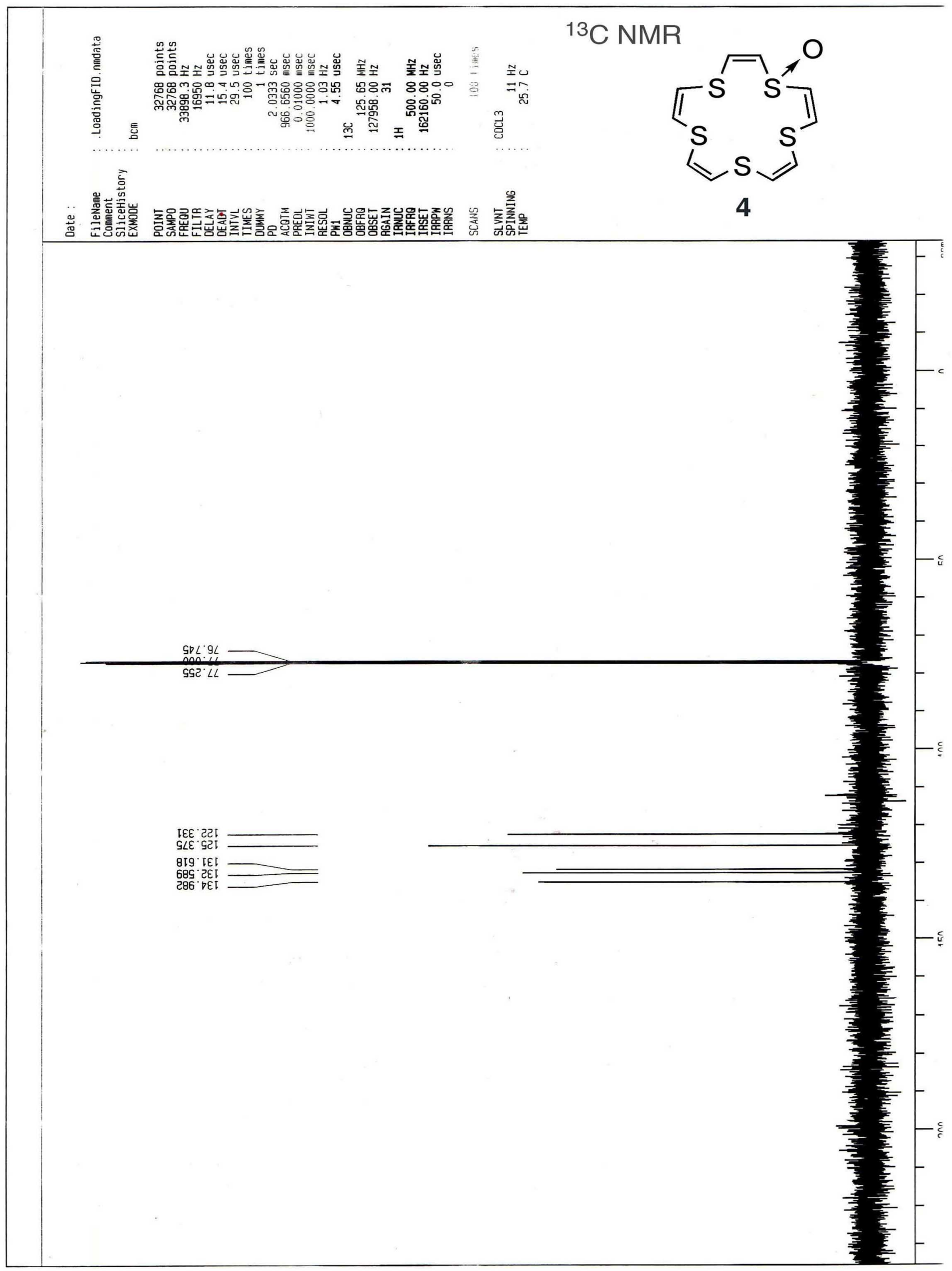




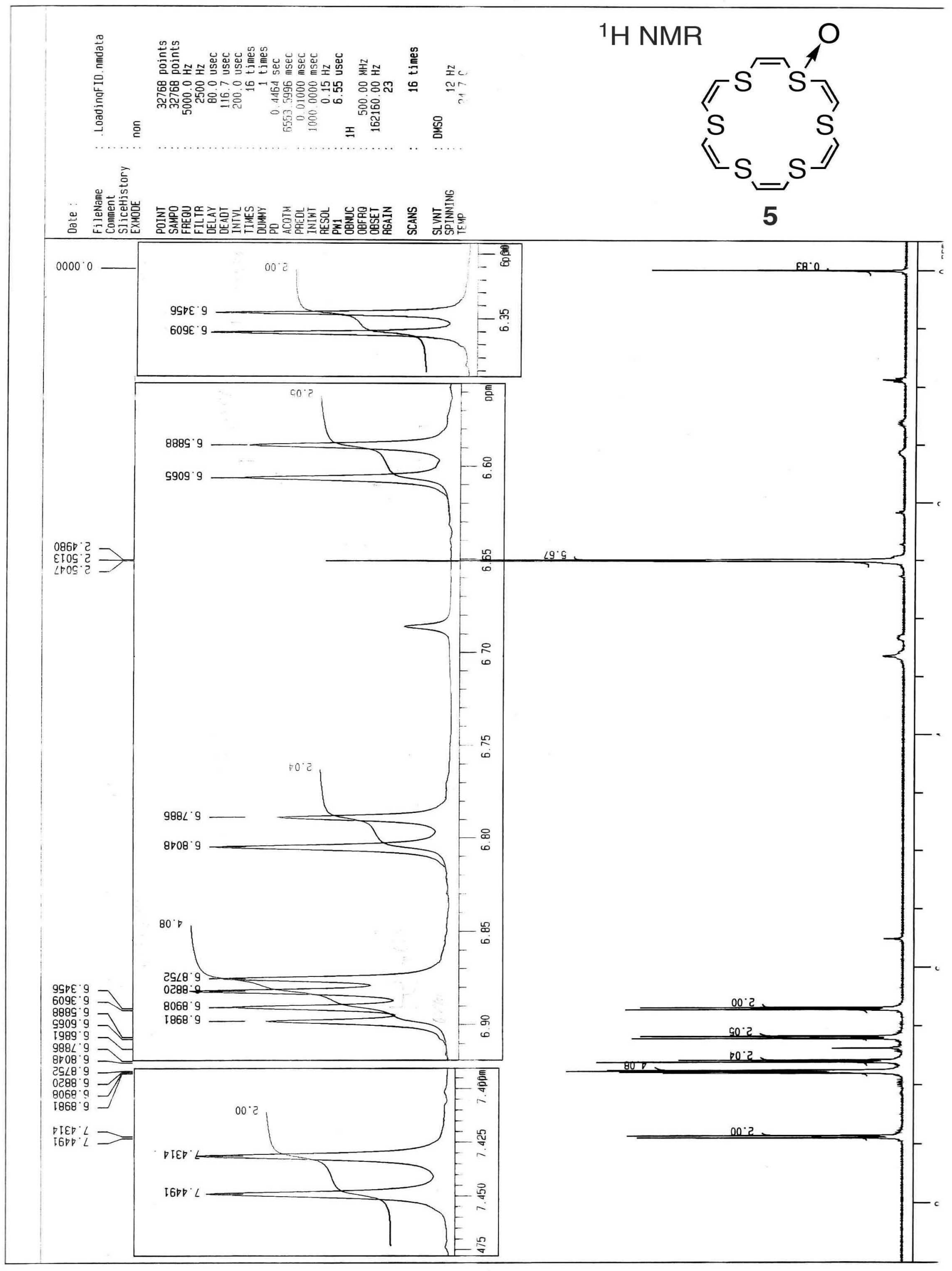




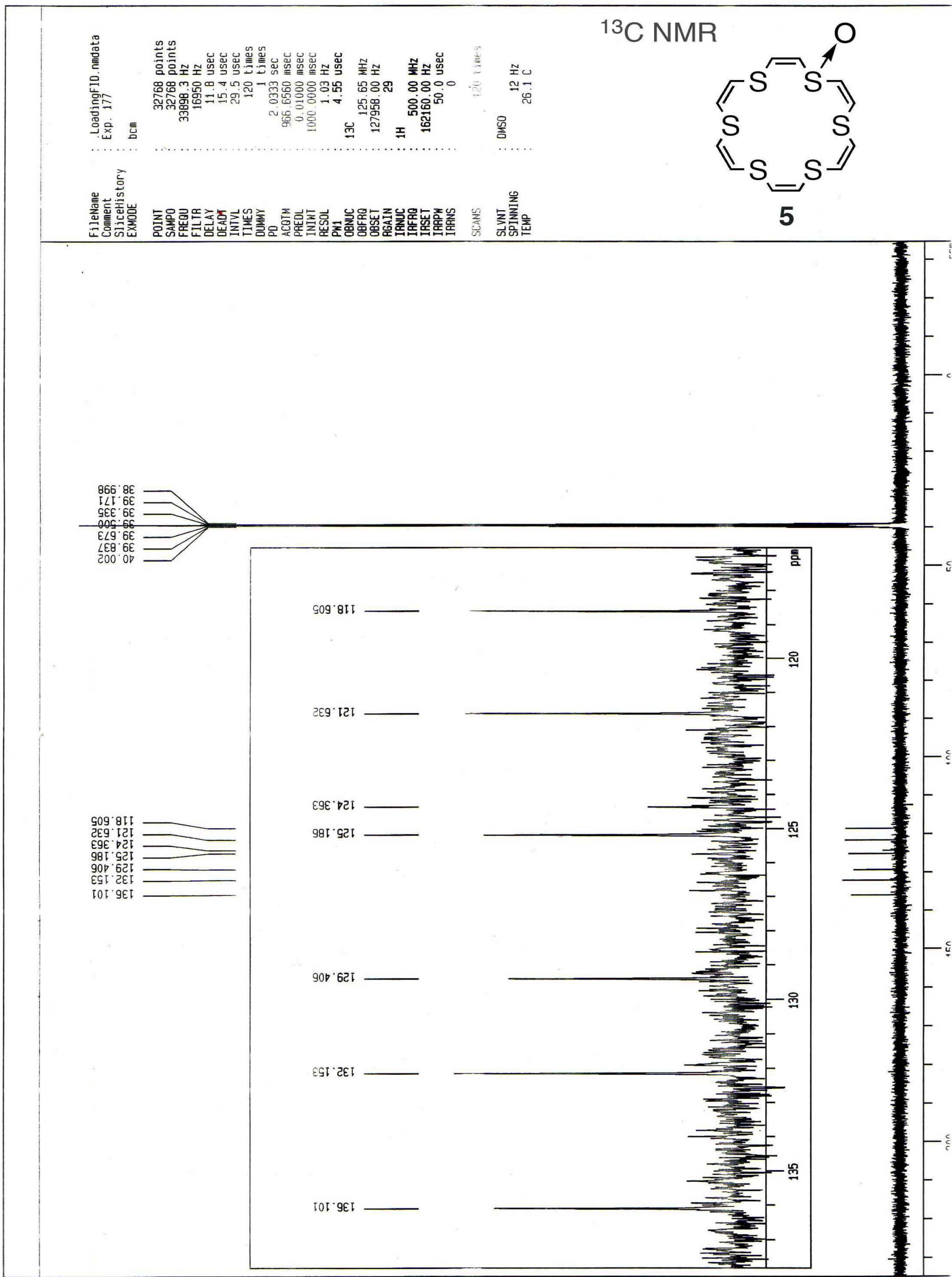




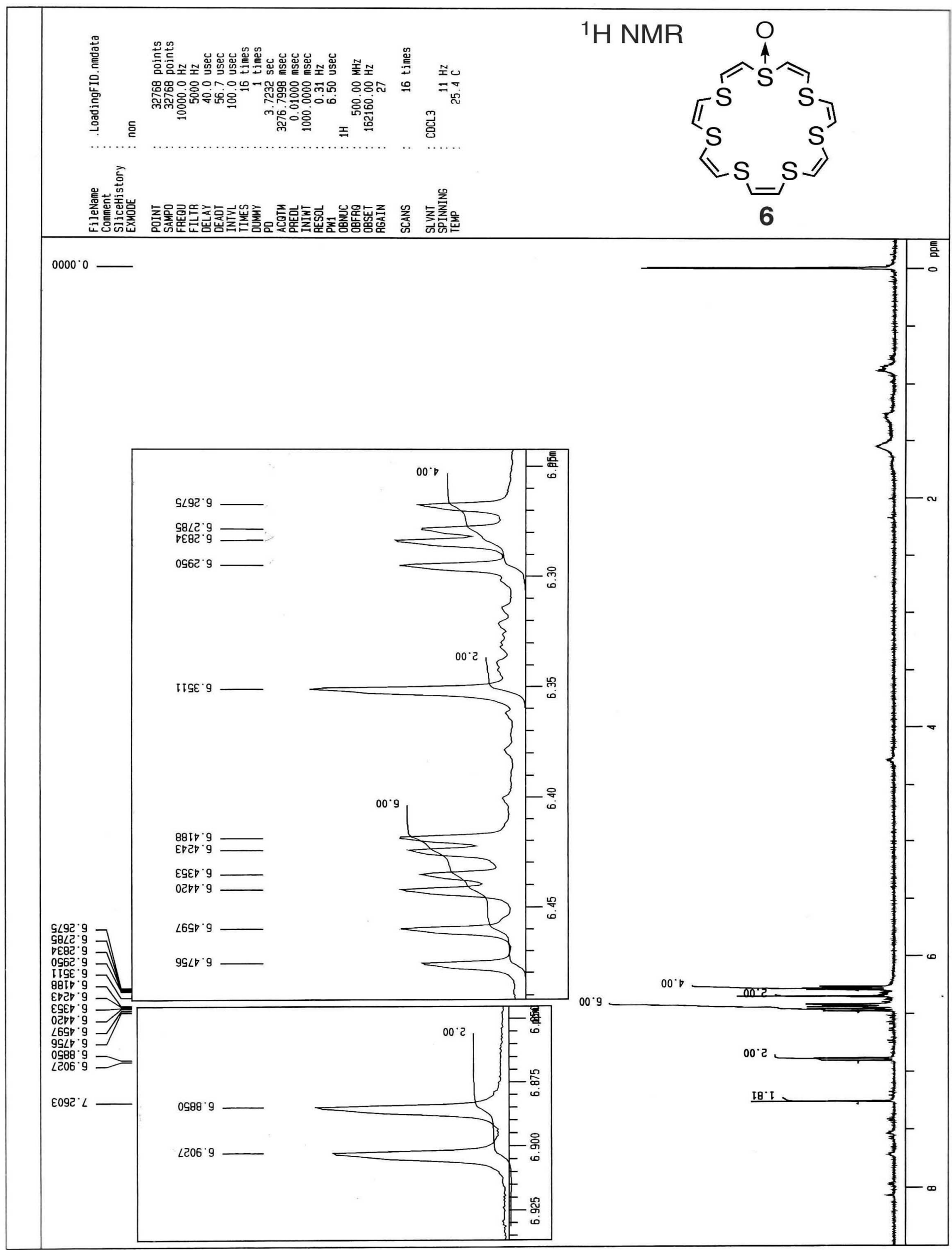




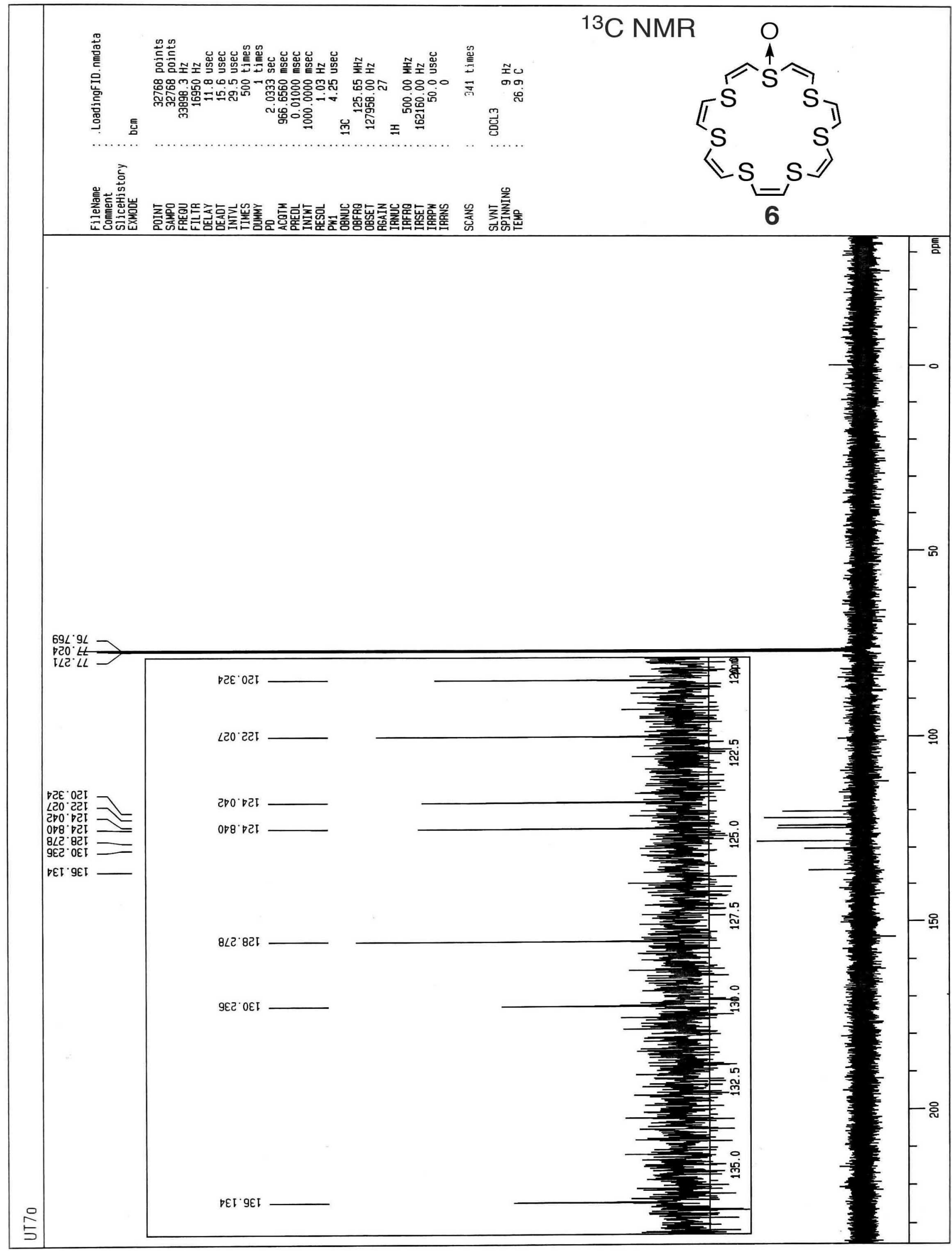




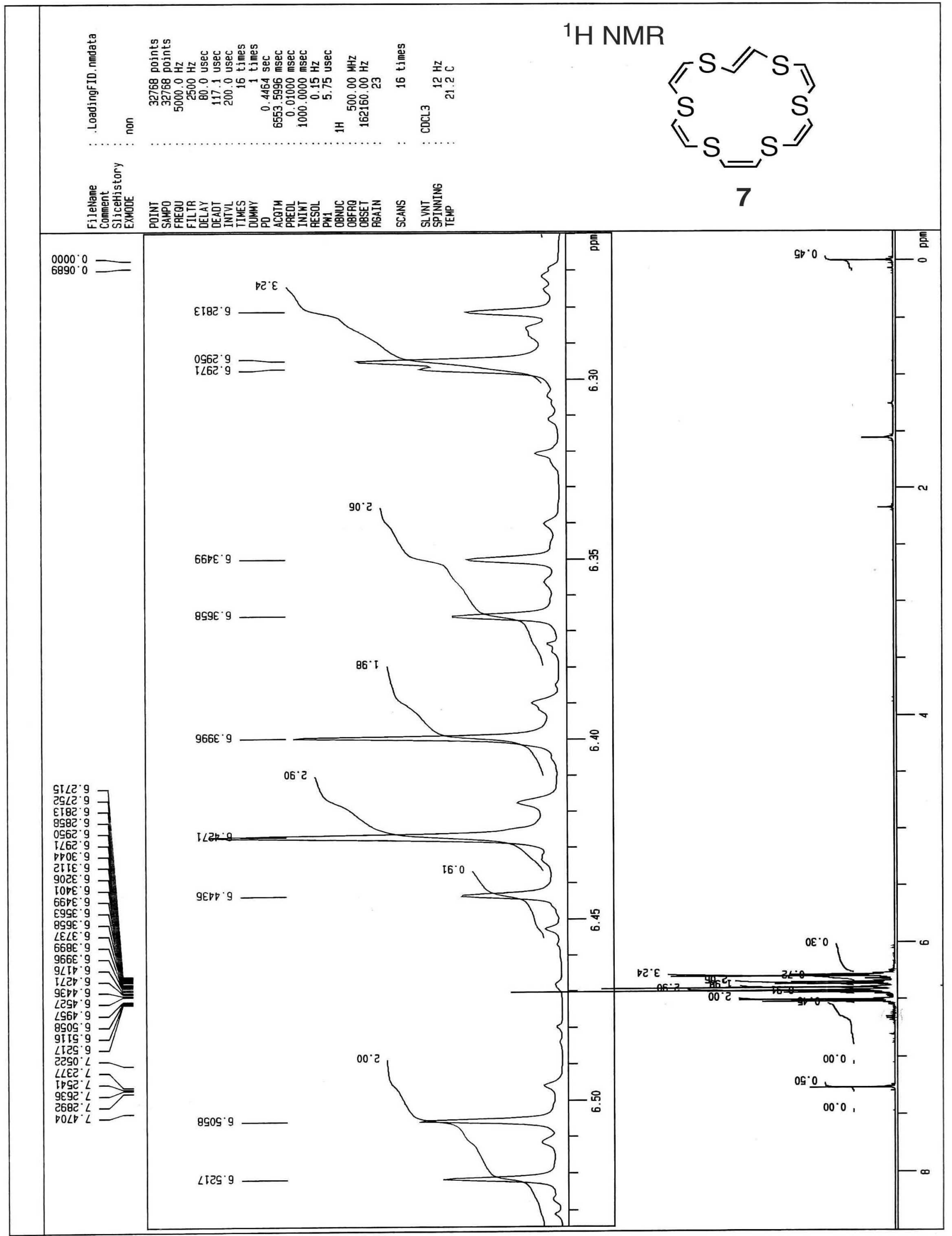




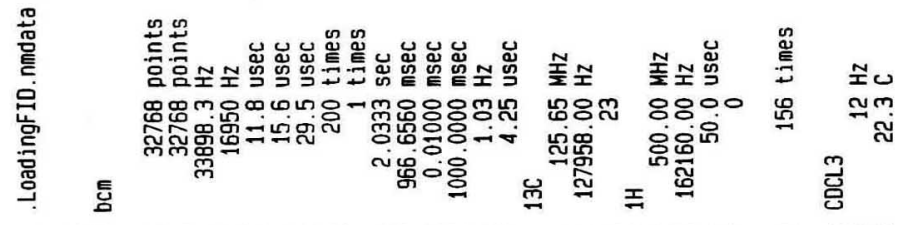

\section{${ }^{13} \mathrm{C}$ NMR}

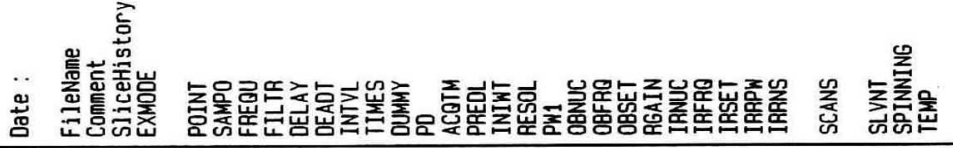
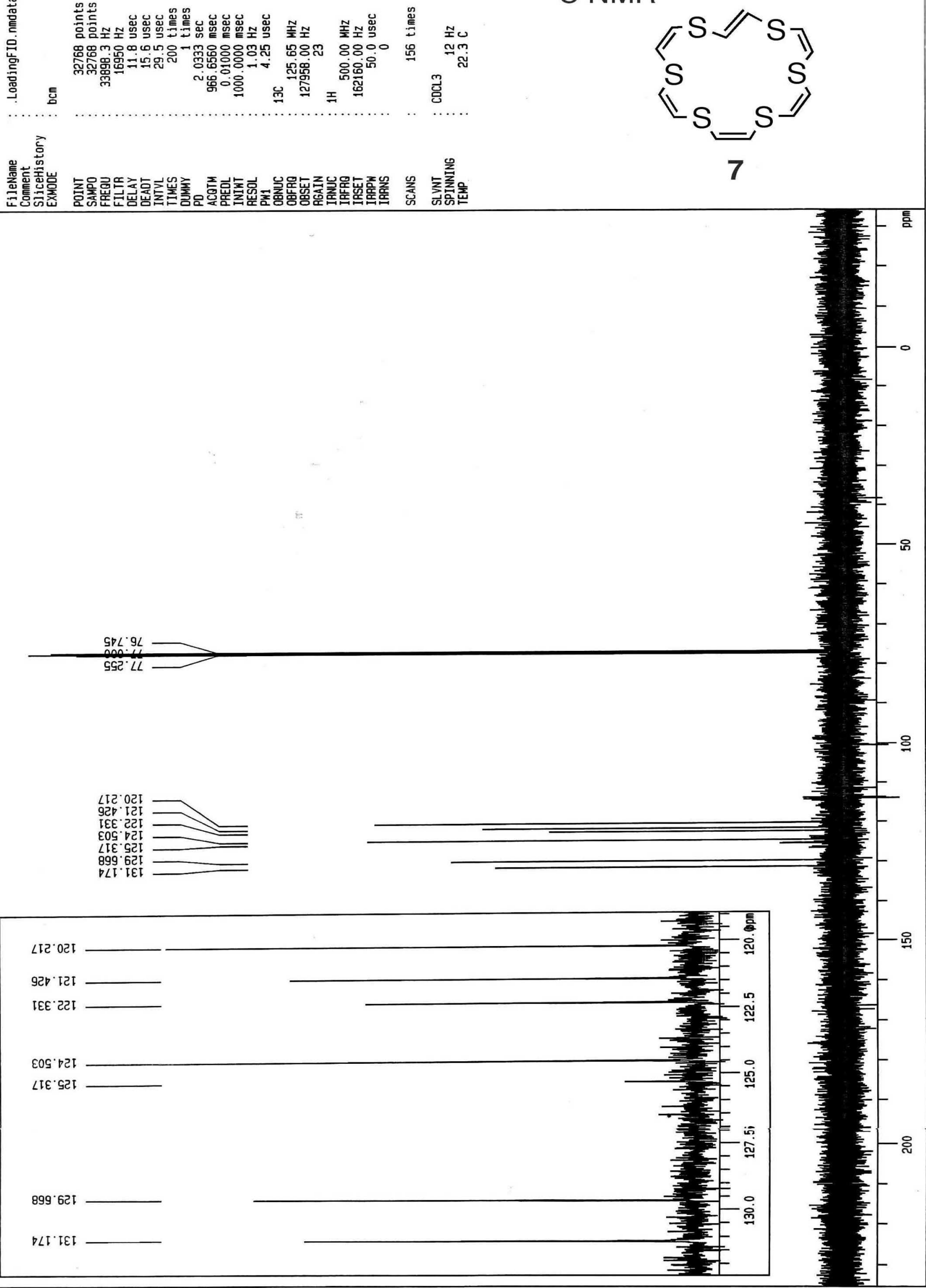


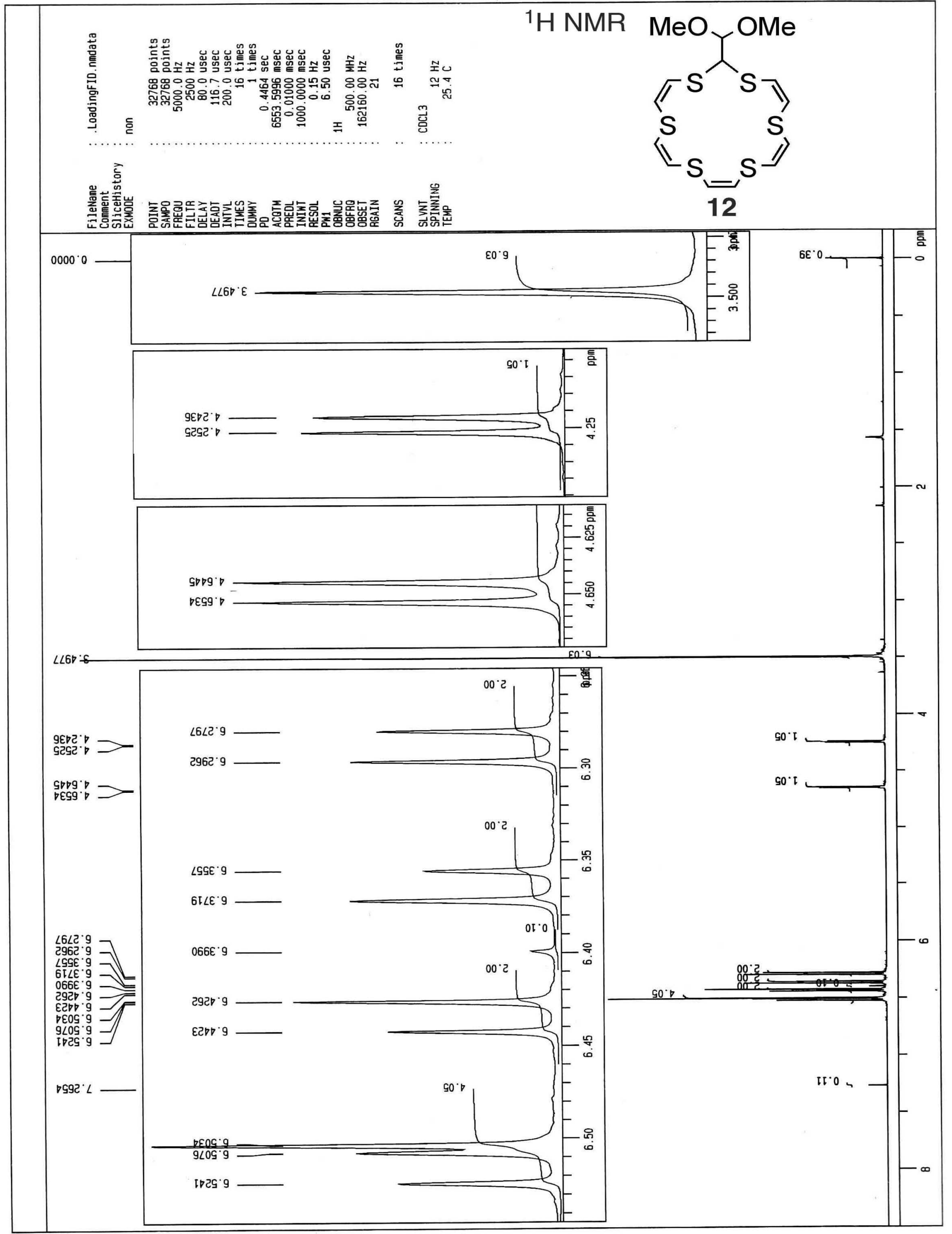




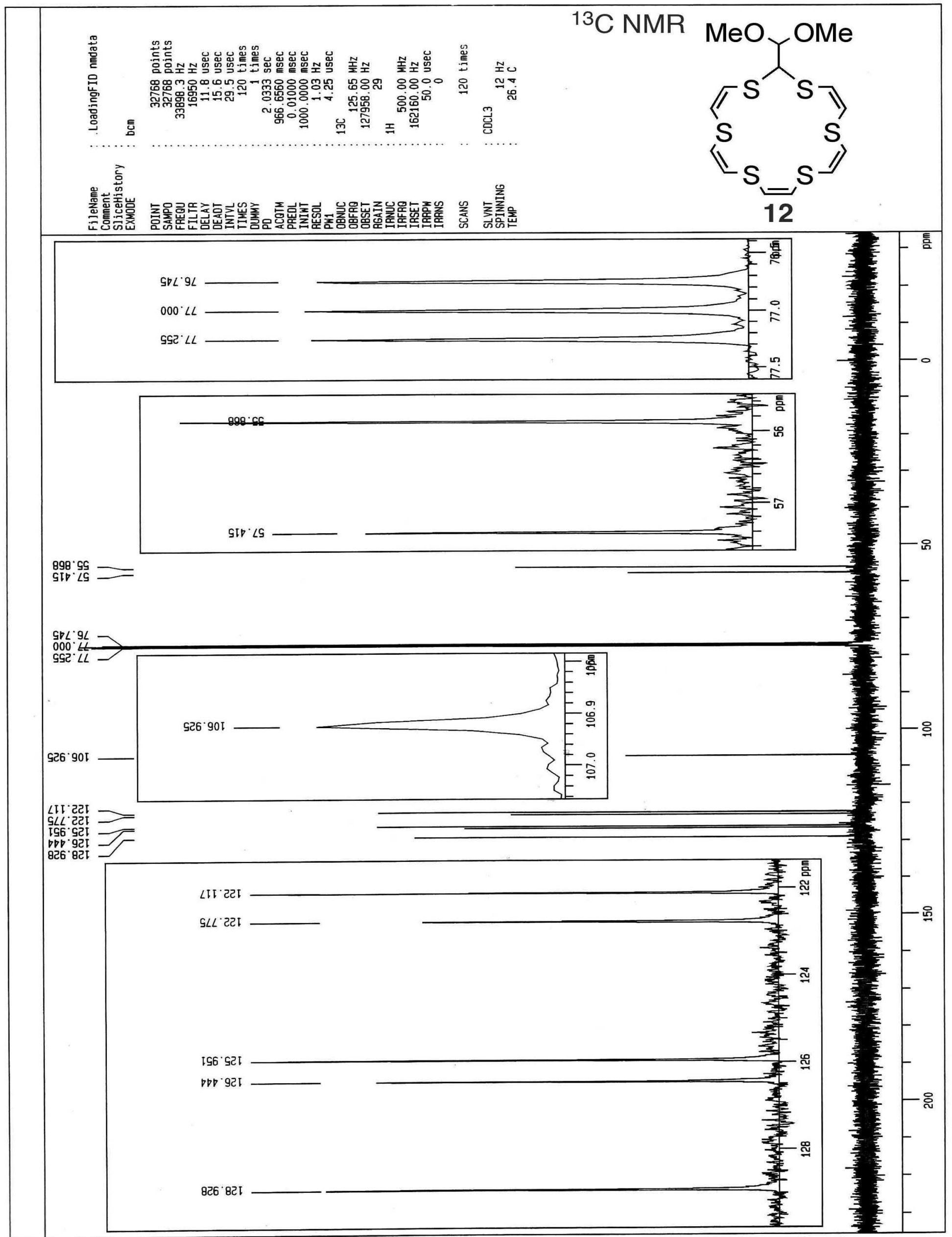

